\title{
Effects of Chronic Psychosocial Stress on Reduction of Basal Glucocorticoid Levels and Suppression of Glucocorticoid Levels Following Dexamethasone Administration in Animal Model of PTSD
}

\author{
Ana Starcevic ${ }^{1}$, Sasa Petricevic ${ }^{1}$, Vuk Djulejic ${ }^{1}$, Zoran Radojicic ${ }^{2}$, Branislav Starcevic ${ }^{3}$, Branislav Filipovic ${ }^{1}$ \\ ${ }^{1}$ Institute of Anatomy Niko Mlljanic, Medical Faculty, University of Belgrade, Dr Subotica 4/2, Belgrade 11000, Serbia; \\ 2Department of Statistics, Faculty of Organizational Sciences, University of Belgrade, Belgrade 11000, Serbia; ${ }^{3}$ Emergency \\ Center, Clinical Center of Serbia, Medical faculty, University of Belgrade, Belgrade 11000, Serbia
}

\begin{abstract}
Citation: Starcevic A, Petricevic S, Djulejic V Radojicic Z, Starcevic B, Filipovic B. Effects of Chronic Psychosocial Stress on Reduction of Basal Glucocorticoid Levels and Suppression of Glucocorticoid Levels Following Dexamethasone Administration in Animal Model of PTSD. Maced J Med Sci. 2014 Mar 15; 7(1):18-22. http://dx.doi.org/10.3889/MJMS.18575773.2014.0357.

Key words: posttraumatic stress disorder; animal model; cortisol.

'Correspondence: Dr. Ana Despot Starcevic. Institute of Anatomy Niko Mlljanic, Medica Faculty, University of Belgrade, Dr Subotica 4/2 Faculty, University of Belgrade, Dr Subotica 4/2, Belgrade 11000, Serbia. E-mail
ana.starcevic22@gmail.com

Received: 27-Dec-2013; Revised: 01-Feb2014; Accepted: 04-Feb-2014; Online first: 24-Feb-2014

Copyright: @ 2014 Starcevic et al. This is an open-access article distributed under the terms of the Creative Commons Attribution License which permits unrestricted use, distribution, and reproduction in any medium, provided the original author and source are credited.

Competing Interests: The authors have declared that no competing interests exist.
\end{abstract}

\begin{abstract}
Aim: To further examine the neurobiological mechanisms and their outcomes responsible for the PTSD sequelae induced by laboratory animal model and to explore the effects of chronic psychosocial paradigm. We tested the hypothesis that our animal model of PTSD would display abnormalities in glucocorticoid levels that are manifest in people with PTSD and that psychosocially stressed rats exhibit a significantly greater suppression of corticosterone levels than control rats following the administration of dexamethasone.
\end{abstract}

Methods: Animals were divided into two groups. The experimental group was scheduled to exposure to two types of stressors: double exposure to acute immobilization stress, and combined predator-threat stress and daily social stress. There was also administration of dexamethasone in combination with stress exposure.

Results: There was a statistical difference between masses of thymus in the stress group and stress group with dexamethasone appliance $(p=0.024)$. We found statistical significance between baseline cortisol and stress induced levels of cortisol and between stress induced group and return to baseline group.

Conclusion: Significant changes in HPA activity, reductions in basal glucocorticoid levels and enhanced dexamethasone induced inhibition of glucocorticoid levels have been manifested. All of this is manifested in PTSD patients also as many other stress induces changes.

\section{Introduction}

Posttraumatic stress disorder (PTSD) is a severe condition that may develop after a person is exposed to one or more traumatic events [1]. People who develop PTSD respond to a traumatic experience with a fear and helplessness. They often endure chronic psychosocial distress by repeatedly reliving their trauma through intrusive, flashback memories [2]. The re-experiencing and avoidance symptoms of the disorder significantly hinder everyday functioning in PTSD patients and foster the development of several additional debilitating symptoms, including persistent anxiety, exaggerated startle, cognitive impairments [3]. Most people who experience a traumatizing event will not develop PTSD and among them in this group are children, especially under the age of ten. The natural response to trauma is recovery, and only a subset of traumatized individuals develops chronic forms of the disorder.

Posttraumatic stress disorder is characterized by a complex aberrant biological profile involving several physiological systems one of which is extensively researched, endocrine system. Hypothalamic-pituitary-adrenal axis (HPA) is altered and empirical investigations of the hormone cortisol report abnormally low baseline cortisol levels [4]. Additionally, some research studies have reported significantly higher stress induced elevations of cortisol in PTSD people compared to controls [5]. 
Trauma induces an enhancement of negative feedback inhibition of the HPA axis. Many studies have reported that PTSD patient's exhibit elevated number of glucocorticoid receptors and adrenocorticotropic hormone following the administration of dexamethasone (synthetic glucocorticoid) [6, 7].

Generally, many studies in the field of posttraumatic stress disorder indicate that cortisol levels are decreased; $\mathrm{CRH}$ receptor sensitivity reduced and enhanced glucocorticoid negative feedback at the level of pituitary gland. All data presenting PTSD findings in the field of PTSD are not consistent which leads us to the fact that heterogeneity is widely present in the manifestation of trauma and the measurement of posttraumatic stress disorder in different people.

Development of appropriate animal models is critical for studying the cellular, molecular, and behavioural mechanisms that underlie the formation and persistence of PTSD psychopathology.

The aim of the present experiments was to further examine the neurobiological mechanisms and their outcomes responsible for the PTSD sequelae induced by laboratory animal model and to explore the effects of chronic psychosocial paradigm. Specifically, the present set of experiments were designed to test the hypothesis that our animal model of PTSD would display abnormalities in glucocorticoid levels that are manifest in people with PTSD and to test hypothesis, that psychosocially stressed rats exhibit a significantly greater suppression of corticosterone levels than control rats following the administration of dexamethasone.

\section{Material and Methods}

\section{Rats}

Adult male Wistar albino rats of about $225 \mathrm{~g}$ of body mass were used for the experiment. The animals were raised in the vivarium of Galenika a.d.

The animals were kept in two under the conditions of alternating 12-hour light and dark intervals, in macrolon cages with steel wire covers. The cages were properly marked. The temperature and relative humidity conditions in the animal room were $18^{\circ} \mathrm{C}$ and $22^{\circ} \mathrm{C}$, with $55-65 \%$, respectively. The conditions were recorded on a daily basis. The animals had free access to food (full feed mixture for rats with $20 \%$ of raw protein content, Veterinary Institute Subotica) and water (from the Belgrade supply grid). Animal care was conducted following the standard operating procedures of Galenika a.d.

The experiment was conducted in compliance with the current national (Animal Welfare Law) European (Directive 2010/63/EU; European convention for the protection of vertebrate animals used for experimental and other scientific purposes) and international legislation and standards (ISO 10993-2: 2006 (E) Animal Welfare Requirements; International Guiding Principles for Biomedical Research Involving Animals).

\section{Experimental Procedure}

Following a 7-day acclimatization period, the animals were divided in 2 groups: animals to be exposed to stress (experimental group 16 animals) and animals kept away from stress (control group, 8 animals). The experimental group was scheduled to exposure to two types of stressors: double exposure to acute immobilization stress, and combined predator-threat stress and daily social stress. The experimental procedure is based on the procedures described by Zoladz (2008) [8] and Zoha and associates (2009) [9].

\section{Acute stress}

On the first day, the experimental group animals were immobilized in plastic rat-immobilization tubes with the bottom covered by the material taken from a cat toilet box. The material was available for cat urination and defecation for at least the previous 48 hours. The treatment duration was 20 minutes after which the animals were released and taken back to their cages. The procedure was repeated 10 days later. The first stress was imposed during the daylight, between 9 and $11 \mathrm{AM}$, and the second was imposed in the dark, between 7 and 9 PM (scheme indicating of different stressors).

\section{Psychosocial stress (paradigm)}

Starting from the second day, the experimental-group animals were exposed to social stress on a daily basis. They were placed in two per cage but the pairs were exchanged on a daily basis with those in different cages of the experimental group taking care that the time elapsed before re-matching the two original animals is not less than 48 hours. The total experiment time was 31 day. The control rat group was not exposed to any type of stress.

\section{Pharmacological treatment}

Twenty one day after the second acute stress imposition, the experimental group was divided into 2 subgroups and dexamethasone (50 mcg/ $/ \mathrm{kg} \mathrm{b.m.)} \mathrm{was}$ administered in a subcutaneous injection to one of them.

\section{Blood sampling and processing}

Blood samples of all animals (in both the experimental and control group) were taken 21 days after the exposure of animals to the second acute 
stress according to the following procedure: blood samples were first taken from the animals before exposure to the stress by placing the animals into plastic immobilization tubes for 20 minutes. Blood from those animals were sampled again after they had been released from the immobilization tubes and the animals were placed into cages to rest. Blood was sampled for the third time two hours after animal release from the immobilization tubes (Fig. 1).

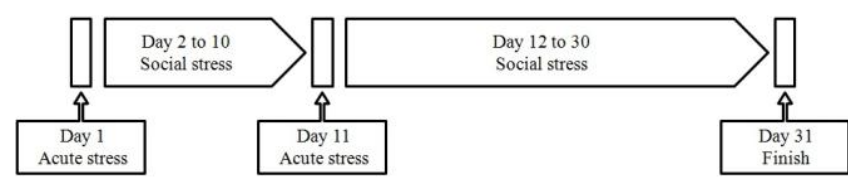

Figure 1: Flow chart of the experimental model.

The blood samples were taken from the sublingual vein (our modification of the method described by Zeller et al., 1998) which was punctured by a $0.6-\mathrm{mm}$ gauge needle [10]. The sampled amount of $0.5 \mathrm{ml}$ of blood was allowed to stay at room temperature to clot (for about 20 minutes) and centrifuged at $5000 \mathrm{rpm}$ for 5 minutes to separate the serum.

The serum sample was tested for cortisol content by a contractual laboratory.

\section{Adrenal gland}

The animals were sacrificed after the third blood sampling by decapitation. The adrenal glands were isolated and weighed.

\section{Results}

For statistical analysis, we used descriptive statistics and exploratory analysis. ANOVA was used for testing differences between groups and LSD test was used for each group testing. Repeated Measure ANOVA was used for testing difference between groups of cortisol levels in different times measuring. Multivariate test for repeated measure, we used Pillai's Trace.

For comparison of the groups, ANOVA was used, and we noticed the following differences between the groups. There was a difference in the weight of thymus $F=4.336 ; p=0.048$ when using Fisher $F$ test (Table 1). In the case of mass thymus using of LSD test showed statistically significant difference between the mass of the thymus in the stress group and stress group with dexamethasone administration $(p=0.024)$. There was no statistical significance in the interaction in group of the administration of dexamethasone and the stress group ( $p>0.05)$.
Table 1: ANOVA analysis.

\begin{tabular}{|c|c|c|c|c|c|c|}
\hline & & \multirow{2}{*}{$\mathrm{N}$} & \multirow{2}{*}{ Mean } & \multirow{2}{*}{ SEM } & \multicolumn{2}{|c|}{ F test } \\
\hline & Group & & & & $\mathrm{F}$ & $p$ \\
\hline \multirow{4}{*}{$\begin{array}{l}\text { Body } \\
\text { mass }\end{array}$} & Stress & 4 & 348.500 & 11.383 & \multirow{4}{*}{0.639} & \multirow{4}{*}{0.550} \\
\hline & $\begin{array}{l}\text { Stress and } \\
\text { dexamethasone }\end{array}$ & 4 & 340.750 & 9.159 & & \\
\hline & Control & 4 & 357.000 & 9.823 & & \\
\hline & Total & 12 & 348.750 & 5.673 & & \\
\hline \multirow{4}{*}{$\begin{array}{l}\text { Thymus } \\
\text { mass }\end{array}$} & Stress & 4 & 0.475 & 0.039 & \multirow{4}{*}{4.336} & \multirow{4}{*}{0.048} \\
\hline & $\begin{array}{l}\text { Stress and } \\
\text { dexamethasone }\end{array}$ & 4 & 0.362 & 0.018 & & \\
\hline & Control & 4 & 0.445 & 0.028 & & \\
\hline & Total & 12 & 0.427 & 0.021 & & \\
\hline \multirow{4}{*}{$\begin{array}{l}\text { Adrenal } \\
\text { mass }\end{array}$} & Stress & 4 & 0.038 & 0.002 & \multirow{4}{*}{1.752} & \multirow{4}{*}{0.228} \\
\hline & $\begin{array}{l}\text { Stress and } \\
\text { dexamethasone }\end{array}$ & 4 & 0.038 & 0.003 & & \\
\hline & Control & 4 & 0.033 & 0.001 & & \\
\hline & Total & 12 & 0.036 & 0.001 & & \\
\hline \multirow{4}{*}{ Cortisol 0} & Stress & 4 & 20.000 & 0.000 & \multirow{4}{*}{ - } & \multirow{4}{*}{ - } \\
\hline & $\begin{array}{l}\text { Stress and } \\
\text { dexamethasone }\end{array}$ & 4 & 20.000 & 0.000 & & \\
\hline & Control & 4 & 20.000 & 0.000 & & \\
\hline & Total & 12 & 20.000 & 0.000 & & \\
\hline \multirow{4}{*}{ Cortisol 1} & Stress & 4 & 42.975 & 1.094 & \multirow{4}{*}{1.268} & \multirow{4}{*}{0.327} \\
\hline & $\begin{array}{l}\text { Stress and } \\
\text { dexamethasone }\end{array}$ & 4 & 34.425 & 8.388 & & \\
\hline & Control & 4 & 32.300 & 2.001 & & \\
\hline & Total & 12 & 36.567 & 2.967 & & \\
\hline \multirow{4}{*}{ Cortisol 2} & Stress & 4 & 20.000 & 0.000 & \multirow{4}{*}{0.711} & \multirow{4}{*}{0.517} \\
\hline & $\begin{array}{l}\text { Stress and } \\
\text { dexamethasone }\end{array}$ & 4 & 25.900 & 5.900 & & \\
\hline & Control & 4 & 26.150 & 4.036 & & \\
\hline & Total & 12 & 24.017 & 2.319 & & \\
\hline
\end{tabular}

Repeated measure ANOVA to analyse the cortisol levels between times measuring in each groups and show statistically significant effect $(F=$ 30.762; $p<0.001)$. Tests of within subject contrasts was statistically significant $(F=15.024 ; p=0.003)$ and test of between subject effects was the same statistically significant $(F=1035.978 ; p<0.001)$. Pairwise comparison between different time measuring we used LSD test and found statistical significance between baseline cortisol and stress induced levels of cortisol $(p<0.001)$ and between stress induced group and return to baseline group $(\mathrm{p}=$ 0.022) (Table 2).

Table 2: Repeated Measurement ANOVA (Pairwise Comparisons).

\begin{tabular}{llrrrrr}
\hline \multirow{2}{*}{ (I) a } & (J) a & $\begin{array}{c}\text { Mean } \\
\text { Difference } \\
\text { (I-J) }\end{array}$ & $\begin{array}{c}\text { Std. } \\
\text { Error }\end{array}$ & Sig. & \multicolumn{3}{c}{$\begin{array}{c}\text { 95\% Confidence Interval for } \\
\text { Difference } \\
\text { Lower Bound }\end{array}$} \\
& & & & Upper Bound \\
\hline \multirow{2}{*}{ Cortisol 0 0 } & Cortisol 1 & -16.567 & 2.967 & .000 & -23.097 & -10.036 \\
& Cortisol 2 & -4.017 & 2.319 & .111 & -9.122 & 1.088 \\
\hline \multirow{2}{*}{ Cortisol 1 } & Cortisol 0 & 16.567 & 2.967 & .000 & 10.036 & 23.097 \\
& Cortisol 2 & 12.550 & 4.701 & .022 & 2.203 & 22.897 \\
\hline \multirow{2}{*}{ Cortisol 2 } & Cortisol 0 & 4.017 & 2.319 & .111 & -1.088 & 9.122 \\
& Cortisol 1 & -12.550 & 4.701 & .022 & -22.897 & -2.203 \\
\hline
\end{tabular}

Pairwise comparing cortisol level in each group was shown in Fig. 2. Statistical significant in stress group was shown between cortisol 1 and other two measurements $(p<0.001)$

Table 3: Paired sample test between groups for each cortisol time measuring.

\begin{tabular}{|c|c|c|c|c|c|c|c|}
\hline Group & & & Mean & $\begin{array}{l}\text { Std. Error } \\
\text { Mean }\end{array}$ & $t$ & df & Sig. \\
\hline \multirow{2}{*}{ Stress } & Pair 1 & $\begin{array}{l}\text { Cortisol } 0 \text { - } \\
\text { Cortisol } 1\end{array}$ & -22.975 & 1.094 & -20.997 & 3 & 0.000 \\
\hline & Pair 3 & $\begin{array}{l}\text { Cortisol } 1 \text { - } \\
\text { Cortisol } 2 \\
\end{array}$ & 22.975 & 1.094 & 20.997 & 3 & 0.000 \\
\hline \multirow{3}{*}{$\begin{array}{l}\text { Stress and } \\
\text { dexame- } \\
\text { thasone }\end{array}$} & Pair 1 & $\begin{array}{l}\text { Cortisol } 0 \text { - } \\
\text { Cortisol } 1\end{array}$ & -14.425 & 8.388 & -1.720 & 3 & 0.184 \\
\hline & Pair 3 & $\begin{array}{l}\text { Cortisol 1 - } \\
\text { Cortisol } 2\end{array}$ & 8.525 & 12.724 & .670 & 3 & 0.551 \\
\hline & Pair 2 & $\begin{array}{l}\text { Cortisol } 0 \text { - } \\
\text { Cortisol } 2\end{array}$ & -5.900 & 5.900 & -1.000 & 3 & 0.391 \\
\hline \multirow{3}{*}{ Control } & Pair 1 & $\begin{array}{l}\text { Cortisol } 0 \text { - } \\
\text { Cortisol } 1\end{array}$ & -12.300 & 2.001 & -6.146 & 3 & 0.009 \\
\hline & Pair 3 & $\begin{array}{l}\text { Cortisol } 1 \text { - } \\
\text { Cortisol } 2 \\
\end{array}$ & 6.150 & 4.971 & 1.237 & 3 & 0.304 \\
\hline & Pair 2 & $\begin{array}{l}\text { Cortisol } 0 \text { - } \\
\text { Cortisol } 2\end{array}$ & -6.150 & 4.036 & -1.524 & 3 & 0.225 \\
\hline
\end{tabular}


At the group dexamethasone, there are no statistically significant differences in the level of cortisol. In control group was detected statistically significant difference between starting level of cortisol (Cortisol 0 ) and measuring time after (Cortisol 1) $(p=$ $0.009)$. There are no other statistical differences found (Table 3).

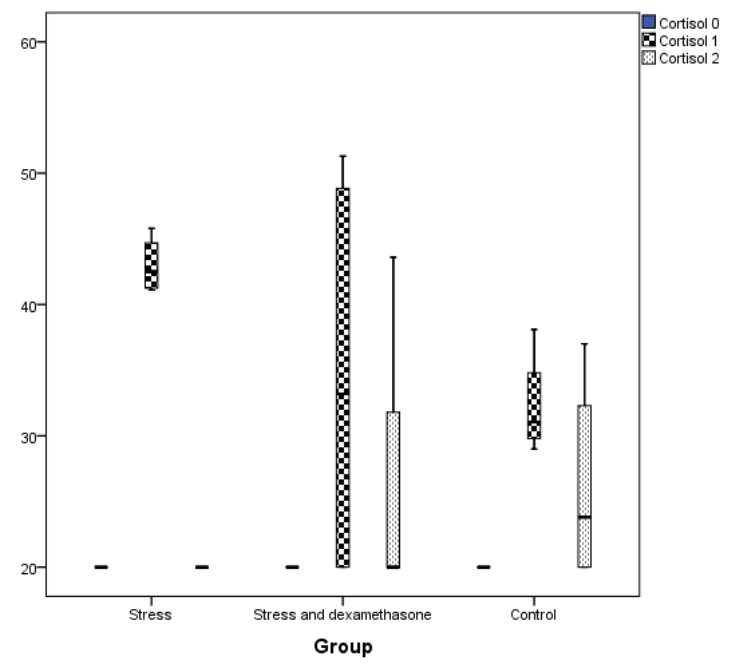

Figure 2: Pairwise comparing cortisol level in each group.

For analysing SPSS statistical software was used. All data was presented as Mean \pm SEM and with statistical significant of $p<0.05$.

\section{Discussion}

Psychosocially stressed rats exhibited significantly larger adrenal glands, significantly smaller thymuses and reduction in growth rate compared to control rats. Rats exposed to chronic psychosocial stress exhibited significantly lower baseline levels of corticosterone than control animals. Several studies have reported abnormally low baseline levels of cortisol in people with PTSD in the early morning hours, when levels of cortisol begin to rise in humans. [11-14] Many animal models have reported that chronic stress, such as daily restraint stress, results in significantly elevated baseline glucocorticoid levels [15-17]. Animal models that have reported significantly reduced baseline glucocorticoid levels have emloyed either the single prolonged stress paradigm or a stress-restress paradigm consisting of situational reminders of the original stress experience [18-20]. Animals that were socially stressed did not show significant acute stress-induced increase in corticosterone levels than control animals. This could be due to the time of day during which the blood samples were collected. Some previous studies have shown that the stress-induced increase in rat corticosterone levels is not as great during the dark cycle as it is during the light cycle [21]. This finding, although unexpected, is consistent with some of the PTSD literature reporting a blunted stress-induced increase in cortisol levels in PTSD patients. Some animal models of PTSD have also reported a blunted glucocorticoid response to acute stress in animals that have developed PTSD-like behaviours. Enhanced negative feedback sensitivity to the synthetic glucocorticoid, dexamethasone is one of the most important finding of the present experiments, which occurs as a result of a chronic psychosocial stress, involving two acute stress exposures and daily social instability.

These data are consistent with a majority of the PTSD literature. A number of studies have reported that PTSD patients have an increased number and sensitivity of glucocorticoid receptors [22] and display an increased suppression of cortisol and ACTH following the administration of dexamethasone.

There were only few studies, which had tested for the presence of enhanced negative feedback inhibition of the HPA axis in PTSD animal model. Rats exposed to a single prolonged stress paradigm subsequently exhibited a blunted restraint stress-induced increase in ACTH levels following the administration of cortisol [23]. Kohda et al. (2007) reported that rats exposed to a single prolonged stress paradigm subsequently exhibited a blunted restraint stress-induced increase in corticosterone levels following the administration of dexamethasone [24]. Both of these reports suggest that the single prolonged stress paradigm produces changes in HPA axis function that resemble enhanced negative feedback inhibition and are comparable to the present set of data.

In conclusion, development of appropriate animal models is critical for studying the cellular, molecular, and behavioural mechanisms that underlie the formation and persistence of PTSD psychopathology.

Useful animal model of PTSD must meet a number of criteria that relate to its validity for studying the human disorder. In our model trauma induction procedures were included that are analogous to those in PTSD patients, such as a treat to survival, a control deprivation, social instability. Rats that were included in our experiments showed changes in their natural physiology and behaviour, which are similar to the PTSD patients. Significant changes in HPA activity, reductions in basal glucocorticoid levels and enhanced dexamethasone induced inhibition of glucocorticoid levels have been manifested. All of this is manifested in PTSD patients also as many other stress induces changes.

\section{References}

1. American Psychiatric Association. Diagnostic and Statistical Manual of Mental Disorders (Fifth ed.). Arlington, VA: American Psychiatric Publishing. 2013: 271-280

2. Speckens AE, Ehlers A, Hackmann A, Clark DM. Changes in intrusive memories associated with imaginal reliving in 
posttraumatic stress disorder. J Anxiety Disord. 2006; 20: 328341.

3. Brewin CR, Andrews B, Valentine JD. Meta-analysis of risk factors for posttraumatic stress disorder in trauma-exposed adults. $J$ Consult Clin Psychol. 2000;68(5):748-66.

4. Yehuda R, Halligan SL, Golier JA, Grossman R, Bierer LM. Effects of trauma exposure on the cortisol response to dexamethasone administration in PTSD and major depressive disorder. Psychoneuroendocrinology. 2004;29 (3): 389-404.

5. Bremner JD, Elzinga B, Schmahl C, Vermetten E. Structural and functional plasticity of the human brain in posttraumatic stress disorder. Prog Brain Res. 2008; 167: 171-186

6. Yehuda R, Boisoneau D, Lowy MT, Giller Jr EL. Doseresponse changes in plasma cortisol and lymphocyte glucocorticoid receptors following dexamethasone administration in combat veterans with and without posttraumatic stress disorder. Arch Gen Psychiatry. 1995;52, 583-593.

7. Yehuda R, Boisoneau D, Mason JW, Giller EL. Glucocorticoid receptor number and cortisol excretion in mood, anxiety, and psychotic disorders. Biol Psychiatry. 1993;34: 18-25.

8. Zoladz PR, Conrad CD, Fleshner M, Diamond DM. Acute episodes of predator exposure in conjunction with chronic social instability as an animal model of post-traumatic stress disorder. Stress. 2008; 11: 259-281.

9. Zohar J, Matar MA, Ifergane G, Kaplan Z, Cohen H. Brief poststressor treatment with pregabalin in an animal model for PTSD: Short-term anxiolytic effects without long-term anxiogenic effect. Eur Neuropsychopharmacol. 2008;18: 653—666.

10. Zeller W, Weber H, Panoussis B, Burge T, Bergmann R. (1998) Refinement of blood sampling from sublingual vein of rats. Laboratory Animals 32, 369-7611.

11. Yehuda R, Brand SR, Golier, JA et al. Clinical correlates of DHEA associated with posttraumatic stress disorder. Acta Psychiatrica Scandinavica. 2006;114:187-193.

12. Saxe G, Stoddard F, Courtney D, et al. Relationship between acute morphine and the course of PTSD in children with burns. J Am Acad Child Adolesc Psychiatry. 2001;40(8):915-21.

13. Lindauer RTL, Van Meijel EPM, Jalink M., et al. Heart rate responsitivity to Script-driven imagery in posttraumatic stress disorder: Specificity of response and effects of Psychotherapy. Psychosomatic medicine. 2006;68: 33-40.

14. Rohleder N, Joksimovic L, Wolf JM, Kirschbaum C. Hypocortisolism and increased glucocorticoid sensitivity of proInflammatory cytokine production in Bosnian war refugees with posttraumatic stress disorder. Biol Psychiatry. 2004;55(7):745-51.

15. Blanchard DC, Sakai RR, Mc Ewen BS, Weiss SM, Blanchard RJ. Subordination stress: Behavioral, brain, and neuroendocrine correlates. Behav Brain Res. 1993;58: 113-121

16. Kant GJ, Leu JR, Anderson SM, Mougey EH. Effects of chronic stress on plasma corticosterone, ACTH and prolactin. Physiol Behav. 1987;40(6):775-9.

17. Mizoguchi K, Yuzurihara M, Ishige A, Sasaki H, Chui DH, Tabira T. Chronic stress induces impairment of spatial working memory because of prefrontal dopaminergic dysfunction. I Neurosci. 2000;20(4):1568-74.

18. Diehl LA, Alvares LO, Noschang C, et al. Long-lasting effects of maternal separation on an animal model of post-traumatic stress disorder: effects on memory and hippocampal oxidative stress. Neurochem Res. 2012;37:700-707.

19. Harvey BH, Oosthuizen F, Brand L, Wegener G, Stein DJ. Stress-restress evokes sustained iNOS activity and altered GABA levels and NMDA receptors in rat hippocampus. Psychopharmacology (Berl). 2004;175(4):494-502.

20. Harvey BH, Naciti C, Brand L, Stein DJ. Endocrine, cognitive and hippocampal/cortical $5 \mathrm{HT} 1 \mathrm{~A} / 2 \mathrm{~A}$ receptor changes evoked by a time-dependent sensitisation (TDS) stress model in rats. Brain Res. 2003;983(1-2):97-107.

21. Baker DG, West SA, Nicholson WE, et al. Serial CSF corticotropin-releasing hormone levels and adrenocortical activity in combat veterans with posttraumatic stress disorder. Am J Psychiatry. 1999;156(4):585-8.

22. Brigitte AA., Otte $C$, Inslicht $S S$ et al. Pretraumatic Prolonged Elevation of Salivary MHPG Predicts Peritraumatic Distress and Symptoms of Post-Traumatic Stress Disorder. J Psychiatr Res. 2011; 45(6): 735-741.

23. Liberzon I, Sripada CS. The functional neuroanatomy of PTSD: a critical review. Prog Brain Res. 2008;167:151-69.

24. Kohda, K, Harada K, Kato K, Hoshino A, Motohashi J, Yamaji T, et al. Glucocorticoid receptor activation is involved in producing abnormal phenotypes of single-prolonged stress rats: a putative post-traumatic stress disorder model. Neuroscience. 2007; 148: 22 33. 